\title{
Eyes of the Storm: How Citizen Scientists Contribute to Government Forecasting and Risk Communication
}

\author{
Brooke Fisher LiU AND ANita Atwell SeAte \\ University of Maryland, College Park, College Park, Maryland \\ IRINA ILES \\ National Consortium for the Study of Terrorism and Responses to Terrorism, \\ University of Maryland, College Park, College Park, Maryland \\ EMINA HEROVIC \\ Risk Communication and Resilience Program, First-Year Innovation and Research \\ Experience, University of Maryland, College Park, College Park, Maryland
}

(Manuscript received 19 October 2019, in final form 17 January 2020)

\begin{abstract}
Since the 1970s, the National Weather Service has trained citizens to collect, confirm, verify, or supplement radar and other data to contribute to a weather-ready nation. This study examines citizens who volunteer as weather spotters through a case study of an award-winning network. We uncover what motivates citizens to become involved in government science projects. Through the lens of relationship management theory and the related network approach, the study provides some of the first evidence on the benefits and drawbacks of citizens serving as amateur scientists and risk communicators and how these citizen scientists sustain their relationships with government scientists.
\end{abstract}

\section{Introduction}

Tornado disaster risk is increasing across much of the United States as population growth and urbanization place even more people and property in tornado-prone regions (Strader et al. 2017; Ashley and Strader 2016; Simmons et al. 2013; Tippett et al. 2016). Adequately and effectively warning the public about severe weather is a constant challenge. Social scientists have been prolific in researching how to better warn and motivate protective actions among members of the public (e.g., Brotzge and Donner 2013; Casteel and Downing 2016; Liu et al. 2019; Perreault et al. 2014). However, research has been less prolific in understanding how forecasters decide to disseminate severe weather risk communication (Brown et al. 2016; Daipha 2015). Understanding this process can provide fruitful avenues for improvements to the science of communicating weather information.

Weather spotters are an important component of the warning system. Since the 1970s, the National Weather

Corresponding author: Brooke Fisher Liu, bfliu@umd.edu
Service (NWS) has trained citizens to collect, confirm, verify, or supplement radar and other data, thus, "serving as the nation's first line of defense against severe weather" (National Severe Storms Laboratory 2019). "SKYWARN," a volunteer program with over 300000 trained spotters, includes police and fire personnel, 911 dispatchers, emergency management workers, public utility workers, and other concerned citizens (National Weather Service 2019; National Severe Storms Laboratory 2019). In this study, we examine concerned citizens who volunteer as weather spotters through a case study of a Nashville-based network, Nash Severe Weather. In doing so, we uncover what motivates citizens to become involved in government science projects and how they can contribute to the science of weather communication.

Since 2010, Nash Severe Weather has coordinated weather information collected by their trained spotters in the Nashville, Tennessee, area and shared this information on Twitter, via their website, and directly with the NWS Weather Forecast Office (WFO) in Nashville via NWS Chat. Additionally, the cofounders of Nash 


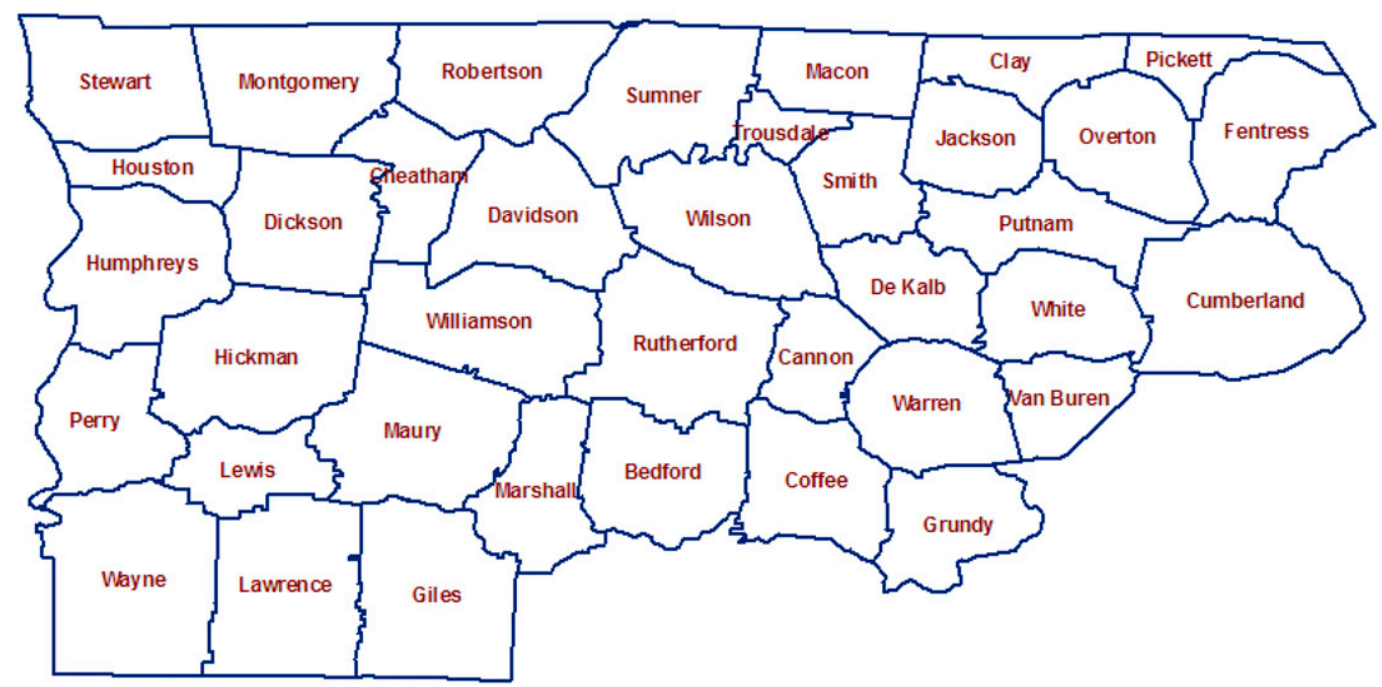

FIG. 1. Nashville WFO Warning Area. Nash Severe Weather provides service to Davidson and Williamson Counties.

Severe Weather monitor radar, manage their own camera network, and staff their own mobile rig to provide original, hyperlocal weather forecasts. In 2016, the founders of Nash Severe Weather received the Walter J. Bennett Public Service Award from the National Weather Association (National Weather Association 2019), making this an ideal case to study to investigate why citizens become involved in government science projects and how government scientists and relevant communities may benefit from citizen scientists' communication efforts. Furthermore, through the lens of relationship management theory (e.g., Ledingham 2003, 2006) and the related network approach (e.g., Yang and Taylor 2015), this case study provides some of the first evidence on the benefits and drawbacks of citizen scientists serving as risk communicators, as well as how these scientists can effectively sustain their relationships with government scientists.

\section{Literature review}

\section{a. Background on Nash Severe Weather}

Founded in 2010, Nash Severe Weather is led by three weather enthusiasts residing in the counties of Davidson and Williamson in Nashville. The group provides "community supported local weather" for two counties (Fig. 1) disseminated via their website and Twitter account, which, at the time of this writing, is followed by over 150000 individuals (Nashville Severe Weather 2019; Seling 2015). Nash Severe Weather describes their goal as providing the residents in these counties with more, easier-to-understand, and actionable information than the information available on mobile weather applications. The group cautions that they are not meteorologists; however, as noted above, they monitor radar, manage their own camera network, and staff their own mobile rig. Additionally, they use radar data and the NWS's internal chat room to communicate severe and hazardous weather information for their counties. Furthermore, Nash Severe Weather functions as the NWS SKYWARN social media coordinators for Nashville. In this capacity, they coordinate and share via Twitter (using the hashtag \#tSpotter) severe and hazardous weather reports received from members of the community (Nashville Severe Weather 2019). In other words, Nash Severe Weather not only functions as a citizen scientist group, as defined in the following section, but also aids the NWS in communicating their weather science to the public.

\section{b. Defining citizen science}

Citizen science is defined as the involvement of members of the public, citizen scientists, "in scientific investigations, data collection, and interpretation of results" (Cappa et al. 2016, p. 374). At its core, citizen science is concerned with knowledge generation and answering authentic research questions (Turrini et al. 2018). Citizen science projects are often initiated by members of the public and aim to influence decisionmaking for public health or conservation purposes (Bonney et al. 2016).

While the majority of citizen science projects are carried out in the fields of biology, conservation, and ecology (Forrester et al. 2017; Jahng and Lee 2018; Kullenberg and Kasperowski 2016; Newson et al. 2017), research regarding citizen science projects is expanding in other areas including emergency management and 
meteorology. Research shows that emergency managers can benefit from citizen scientists to assist in efficiently directing response efforts on the ground predominately through social media (Heaton 2013; Heinzelman and Waters 2010; Kar 2016), as well as to provide real-time assessments of negative health impacts following disasters (McCormick 2012).

Within meteorology, citizen scientists function as storm spotters and storm chasers. Storm spotters are concerned citizens who provide weather observations to law enforcement, emergency managers, and the NWS out of a sense of civic duty (Palmer and Kraushaar 2013). Storm chasers are "nonprofessional scientists who volunteer in scientific activities such as the collection of data, analysis, or dissemination of a scientific project" (Palmer and Kraushaar 2013, p. 296). Citizen science projects include the Cyclone Center (Hennon et al. 2015; Knapp et al. 2016), the Community Collaborative Rain, Hail, and Snow Network (CoCoRaHS; Reges et al. 2016), and the Meteorological Phenomena Identification Near the Ground project (mPING; Elmore et al. 2015) — all of which invite citizens to provide or analyze storm information. The Cyclone Center trains citizens through their online portal to analyze tropical cyclone images in order to provide certainty into the storm's intensity (i.e., sustained maximum wind speed) when forecast agencies disagree and overcome pattern recognition issues in automated techniques. CoCoRaHS is a rain gauge citizen science network that collects precipitation data that is made publicly available and used by a variety of stakeholders (e.g., forecasters and hydrologists, farmers, and water managers). The mPING is a smart phone application that allows users with GPS location capabilities to submit an anonymous weather report (National Severe Storms Laboratory 2014). These observations are used to verify and improve precipitation type algorithms for forecasting. Overall, the research record indicates citizen scientists can help the weather enterprise by providing needed in situ observations and analyzing storm data (Elmore et al. 2015; Knapp et al. 2016; Reges et al. 2016).

\section{c. Why citizens become involved in science}

Research on why people engage in citizen science is limited (Domroese and Johnson 2017). One of the main motivators appears to be a desire to contribute to science (Curtis 2015; Haywood 2015). Many citizen science volunteers may already be interested in scientific endeavors (Martin 2017), and contributing to science allows them to deepen their understanding of the problems they face (McCormick 2012). Other motivations include a strong desire to help the environment, acting in accordance to one's values (i.e., feeling good about oneself; contributing to something worthwhile), learning, the opportunity to engage with fellow citizens, and to be in nature (Crall et al. 2013; Domroese and Johnson 2017; Wright et al. 2015). Individuals who coordinate citizen science projects are critical for affording other citizens the opportunity to benefit from these projects (Turrini et al. 2018). Despite the growing body of research on citizen science, there are large gaps in our knowledge about why citizens decide to lead science projects, including how citizen scientists view the purpose and value of their work (Kimura and Kinchy 2016). Accordingly, this study asks the following research question $(\mathrm{RQ})$ :

RQ1: What motivated citizen scientists to create Nash Severe Weather?

\section{d. Citizen science and weather observation: $A$ relationship management approach}

Increasingly, citizens are engaging in weather data collection and sharing these data with government meteorologists (Coleman et al. 2011; Davids et al. 2019; Durage et al. 2013). Citizen scientists in the weather domain are called weather spotters, and they can be trained by the NWS to recognize severe and hazardous weather conditions and report what they see to the NWS (Brotzge and Donner 2013; Coleman et al. 2011; Durage et al. 2013). Citizen scientists' observations of the physical environment in their communities aid government scientists in verifying technology-driven forecasting models; the success of citizen scientists highly depends on "the spatial distribution of the participants" (Gharesifard et al. 2017, p. 382). When spotters are able to supply ground information from key locations, they can be vital in achieving the NWS's mission of protecting life and property (McCarthy 2002) and quickly disseminating severe weather information to the public (Cavanaugh et al. 2016).

For an organization to be successful in achieving its mission, it needs to build and manage meaningful relationships with its strategic constituencies, including relevant stakeholders, organizations, and publics (Bruning and Ledingham 1998; Cheng 2018; Heath 2013; Lee and Jun 2013). According to relationship management theory (e.g., Ledingham 2003, 2006), relationships are states existing between an organization and its strategic constituencies where the actions of one side influence the attitudes and actions of the other, with the goal of providing mutual benefits to all parties involved. This perspective holds that these relationships are built and negotiated through communication (Kent and Taylor 1998; Yang and Taylor 2015). Prior research has noted the relational benefits of volunteer science projects for 
citizens and government scientists (e.g., Cavanaugh et al. 2016), but has not examined deeply how relationship dynamics affect the success of citizen science projects.

The relationship management approach also considers how relationships can be examined through a network perspective (Kent and Taylor 1998; Saffer 2016, 2019; Sommerfeldt 2013), providing useful tools to understanding relationship building in the weather enterprise. This approach advocates examining the characteristics of relationships including emotional intensity, intimacy, and resource reciprocity (i.e., tie strength) (Saffer 2016, 2019; Sommerfeldt 2013; Yang and Taylor 2015). These relationship characteristics for any given relationship are influenced by where the relationship is situated in the constellation of relationships in the network (i.e., embeddedness) (Sommerfeldt 2013; Yang and Taylor 2015). This perspective acknowledges that an organization may not have the resources to build relationships with all relevant parties, but instead should focus attention on building relationships that can fill the gaps between the organization and important strategic constituencies (i.e., structural holes) (Kent et al. 2016; Yang and Taylor 2015). Next, we turn to the benefits and drawbacks of building and maintaining relationships for government scientists and citizen scientists.

\section{BENEFITS AND DRAWBACKS OF CITIZEN SCIENCE}

Congruent with the relationship management approach, the literature indicates that citizen scientists, communities, organizations, and society benefit from citizen science activities. First, through volunteering, citizen scientists build relationships with one another based on a shared interest. These relationships strengthen the sense of community and belonging, potentially helping build resilience and motivate collaboration during disasters (Dillon et al. 2016; Trimble and Berkes 2013). Relatedly, volunteer citizen scientists develop social capital within their communities and expand their own leadership skills (Lawrence 2006; Stedman et al. 2009), which enhances their community's capacity to productively respond to threats (Shirk et al. 2012). In turn, citizen scientists' social capital facilitates the prioritization of community voices in government environmental planning and development processes (Fang et al. 2016).

Second, citizen science more broadly provides an avenue to include members of the public in the management of local ecosystems, while also benefitting the government by providing and/or enhancing monitoring in a cost-effective manner (Dillon et al. 2016; Lewis and Park 2018; Trimble and Berkes 2013). Additionally, citizen scientists can help governments by recording events that occur infrequently because of the ubiquity of smartphones (Lewis and Park 2018).

Third, by participating in science projects, citizens can improve their scientific literacy (Bela et al. 2016; Bonney et al. 2016; Masters et al. 2016; Turrini et al. 2018). According to a systematic review of volunteer environmental monitoring research (Stepenuck and Green 2015), educational outcomes are the most frequently studied effect of citizen science projects. As other research has noted, a scientifically knowledgeable community is more likely to become scientifically engaged and be aware of and able to use science in their everyday lives (Martin 2017). Importantly, enhancing scientific literacy through close collaboration with scientists is likely to also benefit the relationship between science and society (Ballard et al. 2017; Bonney et al. 2016; Haywood and Besley 2014) and help citizens to better connect with the environment by decreasing power differentials between scientists and citizens (Kimura and Kinchy 2016; Pfeffer and Wagenet 2007).

Citizen scientists in the severe weather domain are rarely studied. However, ethnographic work by Daipha (2015) suggests that government scientists at the NWS build relationships with entities that can communicate their messages to the general public, including citizens who serve as weather spotters (Cavanaugh et al. 2016). NWS government scientists typically rely on emergency managers and local broadcast media affiliates to communicate their weather products to local residents. This is because the NWS, as a government agency, historically had little to no communication channels to effectively and broadly disseminate their products to the general public (Daipha 2015), although this seems to be changing given the adoption of social media by weather forecasting offices (Liu et al. 2020).

However, the relationship management approach indicates that there can be relational drawbacks as well, given that involved parties may prioritize their own needs over others (Cheng 2018). In the citizen science literature, one major drawback is the perceived quality of the data collected by citizen scientists (Bird et al. 2014). Specifically, given individuals' varying skills and commitment to a project, decreased precision in measurement and bias (e.g., nonrandom distribution of effort) are likely and they are difficult to address (Bird et al. 2014). Additionally, little is known about how citizen scientists view the use of their unpaid labor, leading to "larger questions about the science funding regime and the sharing of benefits arising from volunteer labor" (Kimura and Kinchy 2016, 340-341). Furthermore, hierarchical barriers exist that can make 
it challenging for some citizens to volunteer for government science projects (McCauley et al. 2019). Additionally, data produced by citizen scientists may not be as valid and reliable as data produced by trained scientists (de Weger et al. 2014; Lewis and Park 2018).

Given the above discussion, we pose the following research questions:

RQ2: How do the creators of Nash Severe Weather and government scientists build and maintain their relationship?

RQ3: How, if at all, does Nash Severe Weather provide benefits to the National Weather Service by facilitating communication of weather science to the public?

RQ4: What, if any, are the additional relational (i) benefits and (ii) drawbacks of engaging in citizen science according to government scientists at the National Weather Service and citizen scientists at Nash Severe Weather?

\section{Method}

\section{a. Data collection}

Our case study relied upon several data streams collected through a rapid multisited ethnography at the NWS field office in Nashville between 27 February and 6 March 2018. These data are from a larger project examining NWS forecasters' decisions to warn about tornadoes in the southeastern United States. We selected this general timeframe in conjunction with three Science and Operations Officers because of the prevalence of tornadoes during this timeframe in this region. The team entered the field after four verified tornadoes occurred on 24 February 2018, enabling us to access real-time emergency documents and protocols (Horsley 2012). A multisited rapid ethnography is a " $2-4$ week ethnographic study conducted sequentially at multiple sites, consulting independent informants and involving interactive shadowing, observation, and interview data supplemented by secondary data" (Halme et al. 2016, p. 115). This approach allows for gathering insights and understanding from multiple sites, while recognizing time and budget constraints that researchers and participants face (Halme et al. 2016). Importantly for this study, the multisited ethnographic approach allowed us to collect data during and immediately after tornadic weather. Ethnography allows researchers to witness events as they naturally occur (Emerson et al. 2011), straddling "structured research design and improvised inquisitive adventure" (Harrison 2014, p. 224).

The researchers spent $60 \mathrm{~h}$ in the field during which they conducted nine semistructured interviews with
NWS scientists and one semistructured group interview with the three founders of Nash Severe Weather. Forecaster interview guides were developed before entering the field and were tailored based on whether the participant worked during the severe weather event (i.e., on 24 February 2018) and information learned from previous interviews and ethnographic observations. Forecasters who did not work the severe weather event were asked questions about general severe weather operations, decisions to warn about tornadoes, relationships with key partners, and risk communication tools and strategies. Forecasters who worked the severe weather event answered questions about the specific severe weather event instead of the general severe weather operations questions. The interview guide for Nash Severe Weather was developed in the field once our NWS partners established access for us, in accordance with our approved Institutional Review Board research protocol. This interview guide asked questions about the group's background, strategy and evaluation, relationships with key partners, and their activity during the 24 February 2018 severe weather event. The research team also observed a SKYWARN spotter training, a severe weather operations training for NWS scientists, and NWS scientists at work in the office and in the field. Additionally, researchers received access to NWS Chat, an internal messaging platform that NWS scientists use to communicate with local media and emergency managers. Researchers also received a weather spotter's field guide. During the observation timeframe, researchers gathered 65 Facebook posts, 130 Twitter posts from the specified NWS office's handle, 389 Twitter posts from Nash Severe Weather, and one YouTube video from the specified NWS office handle.

\section{b. Data analysis}

Throughout the ethnographic observation, researchers employed field jottings to document initial impressions, notable findings, and emerging patterns. At the end of each observation day, researchers transferred their jottings into more structured field notes to provide a "stepby-step story of what was observed" (Emerson et al. 2011, p. 55). As recommended by disaster sociologists, researchers met daily to discuss what they had learned and follow-up needs (Quarantelli 2002). These daily meetings along with the field notes provided early data analysis of potential codes and emerging themes. After the data were collected, researchers engaged in formal data analysis, employing codes from the field notes and from the extant literature; additional codes emerged inductively during data analysis (Kvale and Brinkmann 2009; Lindlof and Taylor 2011). To code the data, researchers used the qualitative analysis software Dedoose to employ 
Corbin and Strauss's (2015) analytical strategies, including constantly reflecting on the data, looking for negativecase examples, and inquiring about the implications of participants' experiences.

\section{Results}

\section{a. Citizen scientists' motivation to create Nash Severe Weather}

The first research question examines what motivated citizen scientists to create Nash Severe Weather. The data coalesce around three themes: weather passion, provide wall-to-wall weather coverage, and provide hyperlocal weather coverage.

\section{1) PASSION FOR THE WEATHER}

All three creators of Nash Severe Weather have a deep passion for the weather. The founder of the group shared: "So, I'm a weather nerd...My friends started bugging me about it. I got sick of texting them in small increments...so I put it on Twitter." The second citizen scientist who helped create the group shared,

I was doing the same thing, I was listening to amateur radio reports of damage from severe weather. . Both of us were kind of stoked by taking the reports from amateur radio, we knew that the amateur radio reports were credible. And I would take those reports. . put them directly onto Twitter.

The third citizen scientist who contributes to managing Nash Severe Weather likewise is a weather enthusiast. Unlike the other two creators, he has a background in meteorology. As he explained,

I've always been a weather nerd since I was a little kid. . .So I was always glued to the storms...But, I decided not to go into broadcast [meteorology] after college, even though I had already studied for it. Went a different direction and, so, I've never really had an outlet to use my weather knowledge.

\section{2) Provide WALl-To-WAll WeAther COVERAGE}

The creators of Nash Severe Weather take pride in offering $24 \mathrm{~h}$ per day $/ 7$ days per week severe weather coverage when they need to, in part because they are not beholden to financial support from advertisers. As one of the creators shared,

We're wall-to-wall whenever we want to. Right? So, this past weekend when a tornado warning evolved, we don't interrupt the Olympics and make them change the channel. They come find us...We have as high a quality information as any TV station in the country, but we give with an open hand. We don't have commercials.

The creators also are proud that they are able to "beat" local media, and sometimes the Weather Service, in covering severe weather because they can go live on a storm via Twitter any time. The cofounders of Nash Severe Weather relayed an incident when they alerted their public about a likely tornado before local broadcast media and the Weather Service. They shared the following:

Cofounder 1: "We just knew within the next scan, it was gonna be a tough one. And so, I tell you, I wouldn't have seen it in time if a warning was issued."

Cofounder 2: "There was a lot of wind."

Cofounder 1: "I went to go look at the radar and, frankly, [Nashville WFO forecaster name removed] didn't see it."

Cofounder 2: "We caught it when the inflow really picked up and we had a degree signature on that one and we stayed with it even after it left our county. So, normally, we would have left. But, we stayed with it...And so, that was one of those situations when you have the right people working together [to issue a hyperlocal forecast]."

\section{3) PRovide Hyperlocal WeAther COVERAge}

Relatedly, a third reason why the creators of Nash Severe Weather became citizen scientists is to provide hyperlocal weather coverage. As the founder shared,

I think we are successful because we are...what some reporters said a long time ago, 'Eye for local.' Weather service covers 39 counties, TV covers probably more than that. We cover two counties.

The government scientists we interviewed concurred that one of the primary benefits of Nash Severe Weather is their hyperlocal focus that effectively communicates science. As one government scientist noted: "With humor and that really hyper local level. . .They're able to take what we're saying and word it so Joe Blow can understand it and I think they're amazing." Below we review additional benefits of Nash Severe Weather's citizen science.

\section{b. Relationship building among government and citizen scientists}

The second research question investigates how the NWS and Nash Severe Weather have built and maintained their 
relationship. Four themes emerged during data analysis, as explained below.

\section{1) TAKING A CHANCE}

Government scientists and citizen scientists described how their relationship formed through taking a chance. As the founder of Nash Severe Weather recalled,

I sent him [government scientist] an email. 'I'm getting this report way before you guys. Are you looking at this at all?...I was like, 'Look, I'm a lawyer, if I act like an idiot, you can get me disbarred.' And, so we went and sat in a meeting for an hour...and then from there, they [NWS] treated us as the media.

A government forecaster shared a similar story about how the relationship between Nash Severe Weather and their NWS field office began. He said,

That started with our former warning coordination meteorologist. He had been wanting to create some sort of a social media network and then, I think actually Nash Severe Weather came to him first. And, he kind of blew them off the first time, and then the second time he was like oh yeah we could make this work. And we were able to mesh that into the tSpotter network that we have now.

In other words, taking a chance ultimately provided mutual benefits. In the words of one government scientist,

It is a two-way street. They're in Chat every time we've got Chat going in severe weather operations and they're frequently asking questions too. So, they're not just giving us information. We're giving them information. We're answering their questions, and they get to see things right away.

Another reason why the Weather Service and Nash Severe Weather took a chance on building a relationship is that they are "weather nerds" with a passion for the same science. Additionally, Nash Severe Weather and the Weather Service have the same goal: to protect people and property during severe weather.

\section{2) Complementary Functions}

The Weather Service and Nash Severe Weather have sustained their relationship through providing complementary functions. Government scientists focus on forecasting and issuing warnings, and social media sometimes need to be secondary. Conversely, citizen scientists can put social media and public engagement at the forefront. As one government scientist explained,

A lot of times, especially if it's an extremely busy event, the social media takes a back seat. We try to have someone dedicated just to the social media. But even then, it may take a back seat just because so much is going on at the same time when there's a big severe weather event.

Another government scientist shared: "Nash Severe Weather gets the bulk of those [public questions] and they take the time to answer those. God bless them." The Nash Severe Weather citizen scientists agreed. One of them conveyed,

There's people that you can obviously tell are freaking out and it's not a normal kind of being nervous about storms, but are terrified of storms. And, they'll tweet at us at every storm multiple times. And getting the privilege of making them feel a little bit better is awesome.

Nash Severe Weather further complements government scientists by translating science, as discussed later in the results.

\section{3) WEATHER ENTERPRISE FAMILY}

Citizen scientists and government scientists emphasized the importance of out-of-office relationship building, which created a weather enterprise family of sorts. As one of the government scientists discussed,

The Nash Severe Weather guys are super. One of them and his wife opened up their house to the whole group. So, a handful of us Weather Service people and most of the county [emergency management] coordinators all met at their place last year for a big cookout, an afternoon long cookout. . .It wasn't really a business meeting. It was just keeping the relationship going.

Government scientists involve Nash Severe Weather in their community events as well, such as during Severe Weather Awareness Day. Building the weather enterprise family facilitates productive information flow during severe weather, as can be seen in the following interaction on NWS Chat:

$<$ Nash Severe Weather $>$ Pretty dense out there. Someone thinks it's a proper setting for a Steven King novel." < broadcast meteorologist $>$ Are you thinking of issuing a dense fog advisory? < government forecaster $>$ We put an SPS out to cover it for now. Our thinking is that the fog should lighten up as the boundary lifts north over the next few hours. $<$ broadcast meteorologist $>$ Ok thank you [forecaster name removed]!

\section{4) RESPECT AS A FOUNDATION}

At the core of the relationship between Nash Severe Weather and the Weather Service is deep respect. As one of the founders of Nash Severe Weather observed: "It's important that everybody be accountable. We aren't accountable to the [TV] station manager, but we're accountable to the Weather Service." Along the 
same lines, a government scientist characterized Nash Severe Weather as follows:

If you look at their comments on the stuff that they put out, they're very well trusted and so we have to capitalize on that. . .make sure that we maintain a great relationship with them.

The majority of government scientists expressed deep respect for Nash Severe Weather, characterizing them as "revolutionary," "amazing," "key partners," "gamechangers," and "very successful."

\section{c. Communicative benefits of citizen science}

The third research question inquired about the benefits Nash Severe Weather provide NWS scientists by facilitating the communication of weather science to the public. Three themes emerged during data analysis: science translation, information conduit, and message redundancy.

\section{1) SCIENCE TRANSLATION}

A primary communicative benefit Nash Severe Weather provides NWS scientists is science translation, enabling the local NWS office to focus on issuing tornado watches and warnings. For example, during a tornado watch, Nash Severe Weather tweeted: "Tornado Watch means conditions are favorable for tornadoes. We are currently under one of these. A warning means take cover! No warnings for us yet." A hallmark of Nash Severe Weather's communication is an informal, often humorous, approach. For example, they tweeted,

If you're in a mobile home now would be a good time to visit family or friends in a more secure structure. You won't have time to drive somewhere if you wait for a warning. Please read the preceding tweets as ProPreparedness not OMG the World is Ending! But it's reasonable to be ready. Get ready, go about your evening, and keep an eye on the weather.

Nash Severe Weather further translates science by sharing with their followers the actions they are taking during storms, as exemplified in the following tweet:

Right now at my house we're locating kids' and parents' helmets and shoes and inhalers and charging our phones and clearing the closet because we are prepared. Helmets may be goofy but the studies show they're the single best thing you can do in the small chance a tornado strikes.

Nash Severe Weather also uses illustrations to translate science. As the leaders of Nash Severe Weather shared,

If I can illustrate something I will, I just will (Speaker 1). Like the DryAir Monster (Speaker 2)...So, we'll take something from the Weather Service...Say there's dry air eating the snow and we'll make some graphic of a monster eating the snow on the radar screen and tweet it...And people understand that. (Speaker 1). People love the DryAir Monster...People have asked for the DryAir Monster (Speaker 3).

\section{2) INFORMATION CONDUIT}

Another communicative benefit of citizen scientists is that they can amplify government risk communication by sharing information with other citizens. When serving as an information conduit, Nash Severe Weather frequently draws their followers' attention back to the NWS, such as in this tweet:

Severe weather update thread, info from @NWSNashville When: Saturday 4 PM to Sunday 2 AM. We're more likely to see impacts toward the latter end of that time frame. Main Threat will be Damaging Straight-Line Winds along with Brief Spin-up Tornadoes Possible and Flash Flooding.

To support Nash Severe Weather's role as an information conduit, government scientists send information directly to Nash Severe Weather, such as in the following post on NWS Chat:

$<$ @nashseverewx $>$ Radar indicated winds seem to be making it to the ground. Big gusts reported up and down the line. Westhaven in Williamson county right now. 04:47<@nashseverewx > \#tSpotter - Large tree down across power lines on raintree dr. In Hendersonville. - 2245 04:52<@nashseverewx> \#tSpotter - uprooted tree on Rossview rd in Clarksville - 2251 PIC $\gg$ Link: https://t.co/M4DMta7hV0.

Indeed, the government scientists we interviewed characterized Nash Severe Weather as "a key partner." This partnership between Nash Severe Weather and the government scientists continues during quiet weather. For instance, Nash Severe Weather encourages their Twitter followers to sign up for NWS trainings and participate in community events sponsored by NWS.

\section{3) Message Redundancy}

The third benefit of citizen scientists is that they provide message redundancy for government scientists' risk communication. For example, the Weather Service tweeted the following after a tornado:

We are still gathering storm reports from Saturday's severe storms. If you have any damage reports or photos you'd like to share with us, please reply below with a location, time, and photo (if you have one) plus use hashtag \#tSpotter!

As can be seen in the quote, the Weather Service used Nash Severe Weather's tSpotter hashtag to target citizen 
scientists. Similarly, Nash Severe Weather used the tSpotter hashtag to invite their followers to help government scientists with damage assessments, as exemplified in the following tweet: "Seeing reports of damage to the Dunn Center. If you see damage, the NWS would love nothing more than to be told about it. Hit us w/a \#tSpotter."

Government scientists praised Nash Severe Weather for relaying their information to the public, as can be seen in the following quote:

tSpotter is amazing, definitely a great tool. And they're all like volunteers, just super into weather and I think for the most part they kind of just relay our information, they're not sending out bogus information, which is really good, really important.

In the same vein, the creators of Nash Severe Weather emphasized the importance of "one weather message." They shared,

So, but there has to be accountability. The accountability means, I can't issue my own tornado warning. . . I have a lot of respect for what they do. Sometimes, I'll have opinions that I'll cut back on a little bit...or I'll go to them [NWS scientists] and say, 'Can I say this?'

\section{d. Additional benefits and drawbacks of citizen science}

The fourth research question uncovers additional relational 1) benefits and 2) drawbacks of engaging in citizen science for NWS and Nash Severe Weather.

\section{1) BENEFITS}

As noted above, providing hyperlocal coverage is a perceived benefit for both Nash Severe Weather and NWS scientists. For government scientists, our data additionally reveal that Nash Severe Weather provides an important situational awareness filter.

\section{2) Situational AwARENESS FILTER}

Situational awareness, or the ability to integrate important data streams from the environment, is important in forecasters' severe weather decision-making (Hoffman et al. 2017). However, government scientists can be overwhelmed by the amount of environmental data available to them at any given time (Daipha 2015; Hoffman et al. 2017). Government scientists agreed that Nash Severe Weather is "a game-changer" in terms of how they verify severe weather. In the words of one government scientist: "We don't need to know everything out there 'cause we'd be overwhelmed. They're sifting through the reports and basically forwarding on the things that they know will be important to us. So, that's been fantastic." Another government scientist echoed how important it is to have Nash Severe Weather filter storm information, stating, "I would hate to work severe weather without them."

\section{3) DRAWBACKS}

The interview data revealed only a few drawbacks. For Nash Severe Weather, the only drawback is how time-consuming their work can be. They shared, "It's some long nights sometimes and we [the Nash Severe Weather cofounders] made a pact to never miss a storm no matter where we were or what we were doing" and "I hate vacations because I'm away from the lab." For the cofounders, "the lab" is their home offices where they monitor radar, spotter reports via the tSpotter Twitter hashtag, live feeds from their camera network, real-time ground truth from their mobile rigs, and information from NWS Chat.

\section{4) DRAWBACKS FOR GOVERNMENT SCIENTISTS}

The NWS scientists discussed more drawbacks. First, a few NWS scientists mentioned minor conflict over severe weather messaging. For example, one scientist shared,

A couple of the forecasters have mentioned that some of the things they [Nash Severe Weather] say might be, what's the term? Maybe usurping their role or maybe they're being more absolute, whereas we're being more, showing the probability or the level of certainty.

The Nash Severe Weather citizen scientists noted that they "have gotten their hand slapped a few times...gotten a few text messages over the years saying 'I wish you hadn't said that", from their NWS partners.

Second, one government scientist expressed concern that the Weather Service may be providing Nash Severe Weather "special information" that other partners may not receive, which could ultimately create tensions within the weather enterprise. Third, one government scientist conveyed unease about diluting the expertise of the Weather Service. He shared,

I think the more that people want to go into a forecasting enterprise, the less you're going to see of the Weather Service being the so-called experts. I think we even see that locally...Nash Severe Weather is kind of rising up to take on somewhat of a forecaster presence.

Frequent probing during the interviews and the ethnographic observations did not reveal additional drawbacks.

\section{Discussion}

In this paper, we reveal how government scientists can partner with citizens to provide potentially life-saving 
weather information. We find support for citizen scientists' role as science communicators, in addition to facilitators of the scientific process, as emphasized in past research both within (Elmore et al. 2015; Knapp et al. 2016; Reges et al. 2016) and outside (e.g., Crall et al. 2013; Curtis 2015; Domroese and Johnson 2017) the meteorological context. Hence, our study shows the importance of taking a communicative approach to understanding citizen science. In addition, our study adds to the nascent body of knowledge on what types of programs permit effective citizen scientists' participation, as called for in a prior systematic review (Stepenuck and Green 2015).

\section{a. Citizens' motivation to engage in science projects}

We first asked what motivated citizens to engage in weather science projects. For Nash Severe Weather, the motivating factors are a passion for weather and their capacity to provide wall-to-wall, hyperlocal weather coverage. Prior research found that citizen scientists have a deep interest in science (Martin 2017) and participating in government projects can increase their scientific knowledge (Brossard et al. 2005), which certainly was true for the creators of Nash Severe Weather, who proudly described themselves as "weather nerds." Prior research also found that one of the main motivators for citizen scientists is to contribute to knowledge (Curtis 2015; Haywood 2015), more specifically the capacity to provide situated knowledge to reflect the experiential background of citizen scientists (McCormick 2012). While our results do indicate the importance of situated knowledge in terms of the hyperlocal weather coverage, our research adds nuance to the literature by showing some citizens become involved in government science projects because they see structural holes they can fill (Kent et al. 2016; Yang and Taylor 2015). Specifically, Nash Severe Weather identified a need for hyperlocal weather coverage whenever storms occur, filling an information gap for citizens of the Nashville area. These findings reveal how citizen scientists can supplement government risk communication by providing tailored messaging for specific populations.

\section{b. A relationship management approach to citizen science}

We took a relationship management approach to understand the relationships between government scientists and citizen scientists (e.g., Ledingham 2003, 2006; Yang and Taylor 2015). This allowed us to uncover the communicative elements of that relationship while also considering the organizational realities inherent in the weather domain. Our second research question inquired how government scientists and Nash Severe Weather built and maintain their relationship. Our data reveal that NWS scientists and Nash Severe Weather citizen scientists build their relationship by taking a chance, providing complementary functions, being a weather family, and having respect as a foundation.

First, our data indicate that building mutually beneficial relationships (e.g., Ledingham 2003, 2006) may start with a bit of serendipity. For scientists and other science practitioners working with citizen scientists, this suggests that being open to the types of groups with whom they build relationships may prove useful. However, the literature recognizes that organizations likely do not have resources to build and maintain relationships with all relevant strategic constituencies and instead may need to be strategic in their relationship development (Cheng 2018; Yang and Taylor 2015). Our data indicate one important way to do this is collaborating with citizen scientists who provide complementary functions to a given organization. Congruent with the network approach to organizational relationships (Kent et al. 2016; Sommerfeldt 2013; Yang and Taylor 2015), organizations that fill structural holes in the network create mutual benefits for the involved parties. In our study, government scientists benefit from Nash Severe Weather's ability to communicate weather risks to the public, giving them the ability to focus on severe and hazardous weather forecasting. In turn, Nash Severe Weather gains informational benefits by having direct access to government scientists. Prior research found large gaps in our knowledge about why citizens decide to lead science projects (Kimura and Kinchy 2016), and our study indicates that filling structural holes is a strong motivator for this case.

Our findings also support a growing body of research highlighting how traditional boundaries between citizens and experts are shifting (Kinchy 2017; Kimura 2019; McCormick 2012). Indeed, our research participants characterized the relationship between citizen scientists and government scientists as both belonging to the weather enterprise family. This blurring of boundaries is successful, in this case, due to a deep respect among citizen scientists and government forecasters.

Our data further underscore the importance of communication in relationship building. Research finds that face-to-face communication between scientists and citizen scientists motivate participation in citizen science projects, as these interactions allow individuals to ask clarifying questions regarding the project and its relevance (Cappa et al. 2016). Our data indicate that face-toface interactions are important because they provide space to deepen meaningful relationships. In addition to the occasional gatherings our participants mentioned (e.g., cookouts, inclusion in Severe Weather Awareness 
day), the interactions Nash Severe Weather have with the Nashville WFO via NWS Chat provide similar benefits to face-to-face interactions, given the informal nature of this communication platform. This finding suggests that, when in-person meetings are not possible, supplying a direct, informal channel through which citizen scientists can interact with scientists in real time may also strengthen relationships and commitment. However, our data reveal that having multiple channels for communication is important, but for that communication to be successful, it still needs to emphasize a deep commitment between the parties.

\section{c. Citizen scientists as science communicators}

Drawing on prior work, we find that one of the benefits that citizen science can add to the weather enterprise is communicating weather science to the public (Daipha 2015). Prior research on citizen science groups in meteorology shows that these groups can be instrumental in completing records on tropical cyclone intensity (Hennon et al. 2015; Knapp et al. 2016), providing in situ observations to improve precipitation algorithms (Elmore et al. 2015), and helping hydrologists create improved river forecasts (Reges et al. 2016). Prior research also indicated that citizen spotters provide important data that can help government forecasters rapidly communicate severe weather information to the public (Cavanaugh et al. 2016). Our study supports prior research, but also extends it to include citizen scientists as peer-to-peer weather communicators. Historically, NWS scientists had limited access to communication channels that reach the general public such as social media. We uncovered three important communication benefits Nash Severe Weather provides to NWS scientists: serving as an information conduit, providing science translation, and offering message redundancy.

Nash Severe Weather also facilitates engagement with other citizens during severe weather. Prior research found that NOAA, including NWS, primarily employs social media during severe weather for one-way communication of risks (Olson et al. 2019). During quiet weather, NWS invests in community building and engagement through their social media (Lindsey et al. 2018; Olson et al. 2019). Our study reveals that citizen scientists can fill a dialogic loop gap (Gharesifard et al. 2017). Specifically, our data show that during severe weather, Nash Severe Weather engages their fellow citizens in conversations that increase understanding about weather phenomenon by translating scientific information from NWS. Furthermore, Nash Severe Weather provides important actions members of the public can take to protect themselves and their families. In short, the citizen scientists in our case contributed to the NWS mission through their science and risk communication.

Prior research also found that citizen scientists provide ground truth information to NWS, which in turn helps NWS forecasters communicate about severe weather. We add that citizen scientists not only facilitate government communication about risks (Cavanaugh et al. 2016), but they also facilitate citizen-to-citizen dialogue about risks. Government scientists in our study appreciate this dialogic loop being filled, so that they can focus on forecasting during severe weather. Overall, the findings point to the importance of identifying specific roles for citizen scientists, ideally roles that complement the work of government scientists. It may be that citizen scientists have the largest impact and show greatest motivation when they self-identify these roles, as was the case with Nash Severe Weather.

Additionally, Nash Severe Weather provides science translation for NWS, and serves as an information conduit to amplify NWS information through providing message redundancy. Prior research identified the following benefits of citizen science: strengthen citizens' sense of community belonging and overall community resilience to disasters, proliferation of scientific democracy, and improving citizen scientists' scientific literacy (Bela et al. 2016; Martin 2017). Our study points to similar benefits for society but adds that there are direct benefits to government agencies. We found that citizen scientists can improve government's access to information that is critical to the scientific process (i.e., curated weather reports), which in turn improves the government's capacity to prepare the public for severe weather events. These benefits follow the work of Gharesifard et al. (2017), who discussed providing high-quality data to scientists and making information available to the public as important attributes of citizen science networks. We further add that citizen scientists not only make information available to the public, but they can also communicate that information such that the public understands it, although the extent to which this effort is successful remains an empirical question.

\section{d. Additional benefits and drawbacks of citizen science}

Our last research question inquired about additional benefits and drawbacks of engaging in citizen science for Nash Severe Weather and NWS scientists. Benefits include that Nash Severe Weather provides a situational awareness filter by sifting through other citizens' weather reports and curating the useful information for government scientists.

In terms of drawbacks, the Nash Severe Weather creators only mentioned one: the time-consuming 
nature of volunteer citizen science work. The government scientists mentioned a few more drawbacks: minor conflicts between Nash Severe Weather and government scientists over severe weather messaging, concern that the NWS may be providing Nash Severe Weather special information that other partners may not receive, and unease that the popularity of Nash Severe Weather may dilute the perceived expertise of the NWS ("usurping their role," in the words of one of our participants). This latter concern echoes the work of Scharrer et al. (2017) who cautioned that science translation (or making science easy) may lead to a detrimental "popularization" of science (p. 1003), such that members of the public may come to believe that their own judgment and understanding of a complex scientific phenomenon can replace that of experts.

Prior research raised a major concern in regard to citizen science: concerns about the quality of data collected by citizen scientists (Bird et al. 2014; Crall et al. 2013). Our study concluded that the opposite was true: Here citizen scientist communities, such as the creators of Nash Severe Weather, vetted data provided by other citizens - thereby providing valuable quality control for their government scientist partners. This finding calls for future research to examine leaders within citizen scientist communities instead of treating citizen scientists as a monolithic group. Our study also extends the framework provided by Gharesifard et al. (2017) by suggesting that citizen science networks, as they continue to evolve, may become multilevel organizations and their attributes should be studied at various levels, as well as how they interact across levels.

Another concern raised in prior research is challenges with recruiting citizen scientists (Irwin 2018), which was not found in our study. Indeed, we found the reverse, in which citizen scientists recruited government scientists to collaborate (i.e., a bottom-up approach). The government scientists in our study recommended working with already established citizen science groups, rather than recruiting new groups, which is an approach that could benefit science initiatives outside of the weather realm.

\section{e. Limitations and directions for future research}

There are limitations to this study. First, we limited our study to a single, award-winning citizen scientist group in the United States to provide a rich analysis. Future research should explore to what extent our findings apply to other groups, including groups outside the United States. Second, we limited our research to a timeframe immediately following a tornado outbreak to gain insights about the role of citizen scientists in the severe weather domain. While our participants did include other severe weather types during interviews and discussions about operations, the bulk of the collected data focused on tornadoes. Hence, future research should examine other severe and hazardous weather contexts, such as hurricanes, to advance knowledge about citizen science in the weather domain. It would also be useful to understand how severe weather networks operate during quiet weather (if at all) and how their work during those times augments government scientists' work. Third, future research should examine how credibility and trust are understood and negotiated in early stages of citizen science projects. The founders of Nash Severe Weather are white collar professionals (e.g., a lawyer) and this may have helped the group initially establish their relationship with the NWS scientists through increased credibility perceptions associated with the founders' professions.

\section{Conclusions}

Through the lens of the relationship management perspective, this study contributes to our growing knowledge on effective citizen science. In our case study, Nash Severe Weather has meaningfully improved the NWS's capacity to predict and warn about severe weather by serving two critical functions: 1) the classic data collection/filtering role of citizen scientists and 2) the role of communicators of weather science. The success of citizen science initiatives in the weather domain may well rest on the government's capacity to embrace citizen scientists as additional eyes on the storm and independent broadcasters of severe weather information.

Acknowledgments. This research was supported by the National Oceanic and Atmospheric Administration VORTEX-SE program through Award NA17OAR4590194. The views and conclusions contained in this document are those of the authors and should not be interpreted as necessarily representing the official policies, either expressed or implied, of the National Oceanic and Atmospheric Administration.

Data availability statement: The ethnography protocol for this project is available online (https://doi.org/ 10.13016/spik-lyk8). We created this guide to provide a consistent, rigorous approach while in the field, which may assist others who conduct similar research.

\section{REFERENCES}

Ashley, W. S., and S. M. Strader, 2016: Recipe for disaster: How the dynamic ingredients of risk and exposure are changing the tornado disaster landscape. Bull. Amer. Meteor. Soc., 97, 767786, https://doi.org/10.1175/BAMS-D-15-00150.1. 
Ballard, H., C. Dixon, and E. Harris, 2017: Youth-focused citizen science: Examining the role of environmental science learning and agency for conservation. Biol. Conserv., 208, 65-75, https://doi.org/10.1016/j.biocon.2016.05.024.

Bela, G., and Coauthors, 2016: Learning and the transformative potential of citizen science. Conserv. Biol., 30, 990-999, https:// doi.org/10.1111/cobi.12762.

Bird, T. J., and Coauthors, 2014: Statistical solutions for error and bias in global citizen science datasets. Biol. Conserv., 173, 144 154, https://doi.org/10.1016/j.biocon.2013.07.037.

Bonney, R., T. Phillips, H. Ballard, and J. Enck, 2016: Can citizen science enhance public understanding of science? Public Understanding Sci., 25, 2-16, https://doi.org/10.1177/ 0963662515607406.

Brossard, D., B. Lewnstein, and R. Bonney, 2005: Scientific knowledge and attitude change: The impact of a citizen science project. Int. J. Sci. Educ., 27, 1099-1121, https://doi.org/ 10.1080/09500690500069483.

Brotzge, J., and W. Donner, 2013: The tornado warning process: A review of current research, challenges, and opportunities Bull. Amer. Meteor. Soc., 94, 1715-1733, https://doi.org/ 10.1175/BAMS-D-12-00147.1.

Brown, V., and Coauthors, 2016: Risk communication and behavior: Best practices and research findings. NOAA Social Science Committee Rep., 66 pp., http://www.performance.noaa.gov/ wp-content/uploads/Risk-Communication-and-Behavior-BestPractices-and-Research-Findings-July-2016.pdf.

Bruning, S. D., and J. A. Ledingham, 1998: Organization-public relationships and consumer satisfaction: The role of relationships in the satisfaction mix. Commun. Res. Rep., 15, 198-208, https://doi.org/10.1080/08824099809362114.

Cappa, F., J. Laut, O. Nov, L. Giustiniano, and M. Porfiri, 2016: Activating social strategies: Face-to-face interaction in technology-mediated citizen science. J. Environ. Manage., 182, 374-384, https://doi.org/10.1016/j.jenvman.2016.07.092.

Casteel, M., and J. Downing, 2016: Assessing risk following a wireless emergency alert: Are 90 characters enough? J. Homel. Secur. Emerg. Manage., 13, 95-112, https://doi.org/ 10.1515/JHSEM-2015-0024.

Cavanaugh, D., M. Huffman, J. Dunn, and M. Fox, 2016: Connecting the dots: A communication model of the north Texas integrated warning team during the 15 May 2013 tornado outbreak. Wea. Climate Soc., 8, 233-245, https:// doi.org/10.1175/WCAS-D-15-0047.1.

Cheng, Y., 2018: Looking back, moving forward: A review and reflection of the organization-public relationship (OPR) research. Public Relat. Rev., 44, 120-130, https://doi.org/10.1016/ j.pubrev.2017.10.003.

Coleman, T. A., K. R. Knupp, J. Spann, J. B. Elliott, and B. E. Peters, 2011: The history (and future) of tornado warning dissemination in the United States. Bull. Amer. Meteor. Soc., 92, 567-582, https://doi.org/10.1175/2010BAMS3062.1.

Corbin, J., and A. Strauss, 2015: Basics of Qualitative Research: Techniques and Procedures for Developing Grounded Theory. SAGE, $431 \mathrm{pp}$.

Crall, A., R. Jordan, K. Holfelder, G. Newman, J. Graham, and D. Waller, 2013: The impacts of an invasive species citizen science training program on participant attitudes, behavior, and science literacy. Public Understanding Sci., 22, 745-764, https://doi.org/10.1177/0963662511434894.

Curtis, V., 2015: Motivation to participate in an online citizen science game: A study of Foldit. Sci. Commun., 37, 723-746, https://doi.org/10.1177/1075547015609322.
Daipha, P., 2015: Masters of Uncertainty: Weather Forecasters and the Quest for Ground Truth. University of Chicago Press, $271 \mathrm{pp}$.

Davids, J., and Coauthors, 2019: Soda bottle science-Citizen science monsoon precipitation monitoring in Nepal. Front. Earth Sci., 7, 46, https://doi.org/10.3389/feart.2019.00046.

de Weger, L. A., P. S. Hiemstra, E. Op den Buysch, and A. J. H. van Vliet, 2014: Spatiotemporal monitoring of allergic rhinitis symptoms in the Netherlands using citizen science. Allergy, $\mathbf{6 9}$, 1085-1091, https://doi.org/10.1111/all.12433.

Dillon, J., R. Stevenson, and A. Wals, 2016: Introduction to the special section moving from citizen to civic science to address wicked conservation problems. Conserv. Biol., 30, 450-455, https://doi.org/10.1111/cobi.12689.

Domroese, M., and E. Johnson, 2017: Why watch bees? Motivations of citizen science volunteers in the great pollinator project. Biol. Conserv., 208, 40-47, https://doi.org/10.1016/j.biocon. 2016.08.020

Durage, S. W., S. C. Wirasinghe, and J. Ruwanpura, 2013: Comparison of the Canadian and US tornado detection and warning systems. Nat. Hazards, 66, 117-137, https://doi.org/ 10.1007/s11069-012-0168-7.

Elmore, K. L., H. M. Grams, D. Apps, and H. D. Reeves, 2015: Verifying forecast precipitation type with mPING. Wea. Forecasting, 30, 656-667, https://doi.org/10.1175/WAF-D14-00068.1.

Emerson, R. M., R. I. Fretz, and L. L. Shaw, 2011: Writing Ethnographic Fieldnotes. University of Chicago Press, 313 pp.

Fang, M. L., R. Woolrych, J. Sixsmith, S. Canham, L. Battersby, and A. Sixsmith, 2016: Place-making with older persons: Establishing sense-of-place through participatory community mapping workshops. Soc. Sci. Med., 168, 223-229, https:// doi.org/10.1016/j.socscimed.2016.07.007.

Forrester, T., M. Baker, R. Costello, R. Kays, A. Parsons, and W. McShea, 2017: Creating advocates for mammal conservation through citizen science. Biol. Conserv., 208, 98-105, https://doi.org/10.1016/j.biocon.2016.06.025.

Gharesifard, M., U. Wehn, and P. Van der Zaag, 2017: Towards benchmarking citizen observatories: Features and functioning of online amateur weather networks. J. Environ. Manage., 193, 381-393, https://doi.org/10.1016/j.jenvman.2017.02.003.

Halme, M., A. Kourula, S. Lindeman, G. Kallio, M. LimaToivanen, and A. Korsunova, 2016: Sustainability innovation at the base of the pyramid through multi-sited rapid ethnography. Corp. Soc. Resp. Environ. Manage., 23, 113-128, https:// doi.org/10.1002/csr.1385.

Harrison, A. K., 2014: Ethnography. The Oxford Handbook of Qualitative Research, P. Leavy, Ed., Oxford University Press, 223-253.

Haywood, B. K., 2015: Beyond data points and research contributions: The personal meaning and value associated with public participation in scientific research. Int. J. Sci. Educ., 6, 239-262, https://doi.org/10.1080/21548455.2015.1043659.

— , and J. C. Besley, 2014: Education, outreach, and inclusive engagement: Towards integrated indicators of successful program outcomes in participatory science. Public Understanding Sci., 23, 92-106, https://doi.org/10.1177/0963662513494560.

Heath, R. L., 2013: The journey to understand and champion OPR takes many roads, some not yet well traveled. Public Relat. Rev., 39, 426-431, https://doi.org/10.1016/j.pubrev.2013.05.002.

Heaton, B., 2013: How emergency managers can benefit from big data. Emergency Management, 23 July, http://www.govtech.com/em/ disaster/Emergency-Managers-Big-Data.html. 
Heinzelman, J., and C. Waters, 2010: Crowdsourcing crisis information in disaster-affected Haiti. United States Institute of Peace Special Rep., 16 pp., http://www.usip.org/sites/ default/files/SR252\%20-\%20Crowdsourcing \%20Crisis \% 20Information \% 20in \%20Disaster-Affected \%20Haiti.pdf.

Hennon, C. C., and Coauthors, 2015: Cyclone Center: Can citizen scientists improve tropical cyclone intensity records? Bull. Amer. Meteor. Soc., 96, 591-607, https://doi.org/10.1175/ BAMS-D-13-00152.1.

Hoffman, R. R., D. S. LaDue, H. M. Mogil, P. J. Roebber, and J. G. Trafton, 2017: Minding the Weather: How Expert Forecasters Think. The MIT Press, 488 pp.

Horsley, J. S., 2012: Planning for spontaneity: The challenges of disaster communication fieldwork. Int. J. Qual. Methods, 11, 180-194, https://doi.org/10.1177/160940691201100301.

Irwin, A., 2018: No PhDs needed: How citizen science is transforming research. Nature, 562, 480-482, https://doi.org/10.1038/ d41586-018-07106-5.

Jahng, M. R., and N. Lee, 2018: When scientists tweet for social change: Dialogic communication and collective mobilization strategies by Flint Water Study scientists on Twitter. Sci. Commun., 40, 89-108, https://doi.org/10.1177/1075547017751948.

Kar, B., 2016: Citizen science in risk communication in the era of ICT. Concurrency Comput. Pract. Exper., 28, 2005-2013, https://doi.org/10.1002/cpe.3705.

Kent, M. L., and M. Taylor, 1998: Building dialogic relationships through the World Wide Web. Public Relat. Rev., 24, 321-334, https://doi.org/10.1016/S0363-8111(99)80143-X.

— E. E. Sommerfeldt, and A. J. Saffer, 2016: Social networks, power, and public relations: Tertius lungens as a cocreational approach to studying relationship networks. Public Relat. Rev., 42, 91-100, https://doi.org/10.1016/j.pubrev.2015.08.002.

Kimura, A. H., 2019: Citizen science in post-Fukushima Japan: The gendered scientization of radiation measurement. Sci. Cult., 28, 327-350, https://doi.org/10.1080/09505431.2017.1347154.

—_, and A. Kinchy, 2016: Citizen science: Probing the virtues and contexts of participatory research. Engaging Sci. Technol. Soc., 2, 331-361, https://doi.org/10.17351/ESTS2016.99.

Kinchy, A., 2017: Citizen science and democracy: Participatory water monitoring in the Marcellus Shale fracking boom. Sci. Cult., 26, 88-110, https://doi.org/10.1080/09505431.2016.1223113.

Knapp, K. R., J. L. Matthews, J. P. Kossin, and C. C. Hennon, 2016: Identification of tropical cyclone storm types using crowdsourcing. Mon. Wea. Rev., 144, 3783-3798, https://doi.org/ 10.1175/MWR-D-16-0022.1.

Kullenberg, C., and D. Kasperowski, 2016: What is citizen science? A scientometric meta-analysis. PLOS ONE, 11, e0147152, https://doi.org/10.1371/journal.pone.0147152.

Kvale, S., and S. Brinkmann, 2009: InterViews: Learning the Craft of Qualitative Research Interviewing. SAGE, $354 \mathrm{pp}$.

Lawrence, A., 2006: 'No personal motive?' Volunteers, biodiversity, and the false dichotomies of participation. Ethics Place Environ., 9, 279-298, https://doi.org/10.1080/ 13668790600893319.

Ledingham, J. A., 2003: Explicating relationship management as a general theory of public relations. J. Public Relat. Res., 15, 181-198, https://doi.org/10.1207/S1532754XJPRR1502_4.

— 2006: Relationship management: A general theory of public relations. Public Relations Theory II, C. H. Botan and V. V. Hazleton, Eds., Lawrence Erlbaum, 465-483.

Lee, J. M., and J. W. Jun, 2013: Explicating public diplomacy as Organization-Public Relationship (OPR): An empirical investigation of OPRs between the US Embassy in Seoul and
South Korean college students. J. Public Relat. Res., 25, 411425, https://doi.org/10.1080/1062726X.2013.795863.

Lewis, Q. W., and E. Park, 2018: Volunteered geographic videos in physical geography: Data mining from YouTube. Ann. Amer. Assoc. Geogr., 108, 52-70, https://doi.org/10.1080/ 24694452.2017.1343658.

Lindlof, T. R., and B. C. Taylor, 2011: Qualitative Communication Research Methods. SAGE, 377 pp.

Lindsey, R., D. Herring, and E. Greenhalgh, 2018: Response by Lindsey, Herring, and Greenhalgh to "A missed opportunity? NOAA's use of social media to communicate climate science.' Environ. Commun., 12, 284-286, https://doi.org/ 10.1080/17524032.2017.1394659.

Liu, B. F., M. Egnoto, and J. Lim, 2019: How mobile home residents understand and respond to tornado warnings. Wea. Climate Soc., 11, 521-534, https://doi.org/10.1175/WCAS-D17-0080.1.

— A. Atwell Seate, I. Iles, and E. Herovic, 2020: Tornado warning: Understanding the National Weather Service's communication strategies. Public Relat. Rev., https://doi.org/10.1016/ j.pubrev.2019.101879, in press.

Martin, V., 2017: Citizen science as a means for increasing public engagement in science: Presumption or possibility? Sci. Commun., 39, 142-168, https://doi.org/10.1177/1075547017696165.

Masters, K., E. Oh, J. Cox, B. Simmons, C. Lintott, G. Graham, A. Greenhill, and K. Holmes, 2016: Science learning via participation in online citizen science. J. Sci. Commun., 15, 1-33, https://doi.org/10.22323/2.15030207.

McCarthy, D. H., 2002: The role of ground-truth reports in the warning decision-making process during the 3 May 1999 Oklahoma tornado outbreak. Wea. Forecasting, 17, 647-649, https://doi.org/ 10.1175/1520-0434(2002)017<0647:TROGTR > 2.0.CO;2.

McCauley, V., P. McHugh, K. Davison, and C. Domegan, 2019: Collective intelligence for advancing ocean literacy. Environ. Educ. Res., 25, 280-291, https://doi.org/10.1080/ 13504622.2018 .1553234$.

McCormick, S., 2012: After the cap: Risk assessment, citizen science and disaster recovery. Ecol. Soc., 17, 706-715, https:// doi.org/10.5751/ES-05263-170431.

Nashville Severe Weather, 2019: About us \& \#tSpotter. Accessed 25 June 2019, https://www.nashvillesevereweather.com/about-us/.

National Severe Storms Laboratory, 2014: mPING. NOAA Fact Sheet, 1 p., https://www.nssl.noaa.gov/news/factsheets/mPING_ Fact_Sheet_2014.pdf.

_ 2019: Tornado detection. NOAA, accessed 25 June 2019, http:// www.nssl.noaa.gov/education/svrwx101/tornadoes/detection/.

National Weather Association, 2019: NWA Annual Awards Program. https://nwas.org/annual-meeting-events/nwa-annualawards-program/.

National Weather Service, 2019: NWS SKYWARN Storm Spotter Program. Accessed 25 June 2019, https://www.weather.gov/ SKYWARN.

Newson, S., H. Evans, S. Gillings, D. Jarrett, R. Raynor, and M. Wilson, 2017: Large-scale citizen science improves assessment of risk posed by wind farms to bats in southern Scotland. Biol. Conserv., 215, 61-71, https://doi.org/10.1016/j.biocon.2017.09.004.

Olson, M. K., J. Sutton, S. C. Vos, R. Prestley, S. L. Renshaw, and C. T. Butts, 2019: Build community before the storm: The National Weather Service's social media engagement. J. Contingencies Crisis Manage., 27, 359-373, https://doi.org/ 10.1111/1468-5973.12267.

Palmer, M. H., and S. Kraushaar, 2013: Volunteered geographic information, actor-network theory, and severe-storm reports. 
Crowdsourcing Geographic Knowledge: Volunteered Geographic Information (VGI) in Theory and Practice, D. Sui, S. Elwood, and M. Goodchild, Eds., Springer, 287-306.

Perreault, M., J. Houston, and L. Wilkins, 2014: Does scary matter? Testing the effectiveness of new National Weather Service tornado warning messages. Commun. Stud., 65, 484-499, https://doi.org/10.1080/10510974.2014.956942.

Pfeffer, M., and L. P. Wagenet, 2007: Volunteer environmental monitoring, knowledge creation and citizen-scientist interaction. The Sage Handbook of Environment and Society, J. Pretty et al., Eds., SAGE, 235-249.

Quarantelli, E. L., 2002: The Disaster Research Center field studies of organized behavior in the crisis time period of a disaster. Methods of Disaster Research, R. A. Stallings, Ed., International Research Committee on Disasters, 94-126.

Reges, H. W., N. Doesken, J. Turner, N. Newman, A. Bergantino, and Z. Schwalbe, 2016: CoCoRaHS: The evolution and accomplishments of a volunteer rain gauge network. Bull. Amer. Meteor. Soc., 97, 1831-1846, https://doi.org/10.1175/ BAMS-D-14-00213.1.

Saffer, A. J., 2016: A message-focused measurement of the communication dimension of social capital: Revealing shared meaning in a network of relationships. J. Public Relat. Res., 28, 170-192, https://doi.org/10.1080/1062726X.2016.1228065.

—, 2019: Fostering social capital in an international multistakeholder issue network. Public Relat. Rev., 45, 282-296, https://doi.org/10.1016/j.pubrev.2019.02.004.

Scharrer, L., Y. Rupieper, M. Stadtler, and M. Bromme, 2017 When science becomes too easy: Science popularization inclines laypeople to underrate their dependence on experts Public Understanding Sci., 26, 1003-1018, https://doi.org/ 10.1177/0963662516680311.

Seling, M., 2015: David Drobny \& Will Minkoff: The weathermen. Nashville Scene, accessed 25 June 2019, https:/ www.nashvillescene.com/home/article/13058440/david-drobnywill-minkoff.

Shirk, J. L., and Coauthors, 2012: Public participation in scientific research: A framework for deliberate design. Ecol. Soc., 17, 29, https://doi.org/10.5751/ES-04705-170229.
Simmons, K. M., D. Sutter, and R. Pielke, 2013: Normalized tornado damage in the United States: 1950-2011. Environ. Hazards, 12, 132-147, https://doi.org/10.1080/17477891.2012.738642.

Sommerfeldt, E. J., 2013: Networks of social capital: Extending a public relations model of civil society in Peru. Public Relat. Rev., 39, 1-12, https://doi.org/10.1016/j.pubrev.2012.08.005.

Stedman, R., B. Lee, K. Brasier, J. L. Weigle, and F. Higdon, 2009: Cleaning up water? Or building rural community? Community watershed organizations in Pennsylvania. Rural Sociol., 74, 178-200, https://doi.org/10.1111/j.1549-0831.2009.tb00388.x.

Stepenuck, K. F., and L. T. Green, 2015: Individual- and community-level impacts of volunteer environmental monitoring: A synthesis of peer-reviewed literature. Ecol. Soc., 20, 19, https://doi.org/10.5751/ES-07329-200319.

Strader, S. M., W. S. Ashley, T. J. Pinger, and A. J. Kremenec, 2017: Observed and projected changes in United States tornado exposure. Wea. Climate Soc., 9, 109-123, https://doi.org/ 10.1175/WCAS-D-16-0041.1.

Tippett, M. K., C. Lepore, and J. E. Cohen, 2016: More tornadoes in the most extreme U.S. tornado outbreaks. Science, 354, 1419-1423, https://doi.org/10.1126/science.aah7393.

Trimble, M., and F. Berkes, 2013: Participatory research towards co-management: Lessons from artisanal fisheries in coastal Uruguay. J. Environ. Manage., 128, 768-778, https://doi.org/ 10.1016/j.jenvman.2013.06.032.

Turrini, T., D. Dörler, A. Richter, F. Heigl, and A. Bonn, 2018: The threefold potential of environmental citizen science-Generating knowledge, creating learning opportunities and enabling civic participation. Biol. Conserv., 225, 176-186, https:// doi.org/10.1016/j.biocon.2018.03.024.

Wright, D., L. Underhill, M. Keene, and A. Knight, 2015: Understanding the motivations and satisfactions of volunteers to improve the effectiveness of citizen science programs. Soc. Nat. Resour., 28, 1013-1029, https://doi.org/ 10.1080/08941920.2015.1054976.

Yang, A., and M. Taylor, 2015: Looking over, looking out, and moving forward: Positioning public relations in theorizing organizational network ecologies. Commun. Theory, 25, 91115, https://doi.org/10.1111/comt.12049. 